\title{
Towards the Innovation Function
}

\author{
Paulo Antônio Zawislak (I), Mauro Borges (2), Douglas Wegner (3), \\ André Santos (4), Cristina Castro-Lucas (5)
}

\begin{abstract}
This paper explores the main elements that influence innovation and the relationships among them. It is pointed out that innovation results from an entrepreneurial action inside an established institutional context, sustained by resources, abilities and competences and with the support of the necessary financial capital. Therefore, it is proposed that innovation is a function (just as the microeconomic production function) composed of entrepreneurship, institutions, capabilities and capital. Each one of these elements is explored individually and the relationships among them are analyzed. It is still suggested that the size of the firm is a moderator in the relationship between these elements and innovation. The study's contribution is the development of a conceptual model.
\end{abstract}

Keywords: innovation, entrepreneurship, institutions, capabilities, capital.

(I) PPGA/EA/UFRGS. Rua Washington Luiz, 855. Porto Alegre, RS, 90.0 10-000, Brazil. Phone: +55 5I 33083728 / Fax:+55 51 3308 399l.paz@ea.ufrgs.br.

(2) PPGA/EA/UFRGS. Rua Washington Luiz, 855. Porto Alegre, RS, 90.0 10-000, Brazil Phone: +55 5I 33083728 / Fax:+55 5I 3308 399l.mborges.adm@gmail.com

(3) PPGA/EA/UFRGS. Rua Washington Luiz, 855. Porto Alegre, RS, 90.0 10-000, Brazil Phone: +55 5 I 33083728 / Fax: +55 5 I 3308 399I. dwegner@ea.ufrgs.br

(4) PPGA/EA/UFRGS. Rua Washington Luiz, 855. Porto Alegre, RS, 90.010-000, Brazil

Phone:+55 5133083728 / Fax:+55 5I 3308 399I.amsantos@ea.ufrgs.br

(5) PPGA/UNB. ICC Norte Módulo 25 sub-solo. Campus Universitário Darcy Ribeiro/UNB. Brasilia, DF, 70.9 10-900, Brazil

Phone: +55 61 3340780 I.cristinaclucas@yahoo.com.br 


\section{Introduction}

The discussions on the differences in countries' economic development suggest that the outcomes are directly related to the amount of investments in technology and innovation. Countries with a report of larger investments in R\&D are the ones that have obtained the largest productivity increases and growths in per capita income along the decades (Larrain, 2006). Lederman and Saenz (2005) present a study with historical data that relate innovation and economic development along forty years. Rich countries have much higher levels of patents and R\&D investments than developing countries. Although there are countries that have had significant increases of innovations generation along the time, Latin American countries are not part of this list. Therefore, a direct relationship is observed among a country's innovation level and the economic development that it reaches in the course of time.

From the firm's point of view, innovation provides temporary competitive advantages because it grants it the monopoly in the exploration of a new market.As Schumpeter (1942) emphasizes, in order to survive every firm needs to participate in the process of creative destruction that unceasingly revolutionizes the economical structure and creates new elements. That is, if new products and processes constantly substitute the old ones, only the innovative firm will be capable to maintain itself in conditions of disputing the market. As consequence, the firms are responsible for the creation and sustentation of innovation dynamics capable of stimulating countries' economic development.

Understanding the elements that impact innovation is, therefore, an indispensable effort so that either firms as countries can obtain better results. With the purpose of discussing the main elements that influence innovation, this paper takes as a starting point the article written by Zawislak, Castro-Lucas and Souza (2007). According to those authors, one of the explanations for firms' innovation rate is entrepreneur's culture and his/her awareness about the importance of investing in R\&D.

Although all innovation is generated from a composed of will, desire, spirit, courage and vision regarding some new idea (entrepreneurship), there are other elements that composes it. In order to generate innovation, it is necessary that the entrepreneurial firm be capable to explore opportunities inside a social-economical-cultural frame (institutions); to develop a group of resources, capacities, abilities and competences (capabilities) to transform ideas in products and services; and to obtain financial resources to sustain the whole process (capital).

The objective of this paper is to present the concept of "inno- vation function" as a set of elements - entrepreneurship, institutions, capabilities and capital - and their inter-relations as a way to explain innovation. We work under the assumption that there is an innovation function just like the microeconomic production function. These elements and inter-relations are discussed and twelve propositions are generated. At the same time, we consider that firms with different characteristics are influenced in distinct ways by these elements. So, different kinds of firms (in this case, represented by different sizes) moderate the relation among the elements and innovation.

The work is composed by more four sections. Initially, innovation elements are individually presented. The following section discusses the relationships between those elements and present a set of propositions. The fourth section explores how different types of firms influence the relationship between these elements and innovation. The last section highlights the study's conclusions and points out possibilities for future researches.

\section{Presenting the Elements}

Innovation can be defined as the application of knowledge to generate technical or organizational changes capable to offer advantages to the firm that accomplishes them. As Dosi (1988) points out, innovation consists on the research, discovery, experimentation, development, imitation and adoption of new products, new productive processes and forms of organizing resources. According to Schumpeter (1942), there are five innovation types: introduction of new production methods; introduction of new products; opening of new markets; conquering of new sources of raw materials and semi-manufactured products; introduction of new organization of an industrial section.

Innovation refers to the knowledge application that is new to the company and not necessarily new to its competitors, to the market or the world. Smaller and incremental changes, more than radical changes, are in the core of innovation process in developing countries. These countries obtain productivity gains through efforts that approximate them of the technological frontier, by the absorption and adaptation of externally developed knowledge, instead of creating new knowledge inside their firms (Goedhuys, 2007).

It is important to discuss what explains innovation, further more than the simple concept of change or creation of something new. We work under the assumption that there is a set of interrelated elements that compose innovation, what means, just like the microeconomic production function, that there should be a sort of "innovation function" to understand the innovative behavior of the firm:

Innovation $=$ f (entrepreneurship, institutions, capabilities, capital) 


\section{Entrepreneurship}

The schumpeterian entrepreneur plays a fundamental role in the innovation process. Zawislak, Castro-Lucas and Souza (2007) argue that behind the organizational structure and innovation process there are vision and propensity to run risks. Behind the entrepreneurial firm - the one who looks ahead to obtain return on R\&D investments, in search of extraordinary profit opportunities - is the entrepreneur. Entrepreneur's core characteristics are change, innovation, creation and identification of new opportunities, necessarily implicating in running risks. In other words, the search for innovation is central in entrepreneur concept, just as conceived by Schumpeter.

Schumpeter (1942) argues that somebody is an entrepreneur in the extent that he/she executes new combinations and stops being it as soon as, after creating his/her business, settles to manage it in the same way in which other people manage their businesses. The routinist manager, who is not capable to notice and to take advantage of the opportunities, offered by science development, discovery of new resources and emergence of new needs cannot be considered an entrepreneur. According to Venkatamaran (1997) entrepreneurship differs from management for being the provider of the economical change. The entrepreneur owns specific individual resources that facilitate the recognition of new opportunities and the arrangement of resources for a business. Entrepreneurial opportunities exist primarily because different agents have different beliefs in the relative value of resources when they are converted from inputs in products.

With the firm's expansion, the entrepreneur's role and his/her culture, behavior and attitude is substituted by the R\&D department, as Schumpeter (1942) has argued. In other words, as the firm grows and develops itself, it becomes impossible to the entrepreneur himself be the only responsible for innovation, so it is necessary to routinize this function.

Influencing factors of the entrepreneurship for innovation are shown in Figure I.

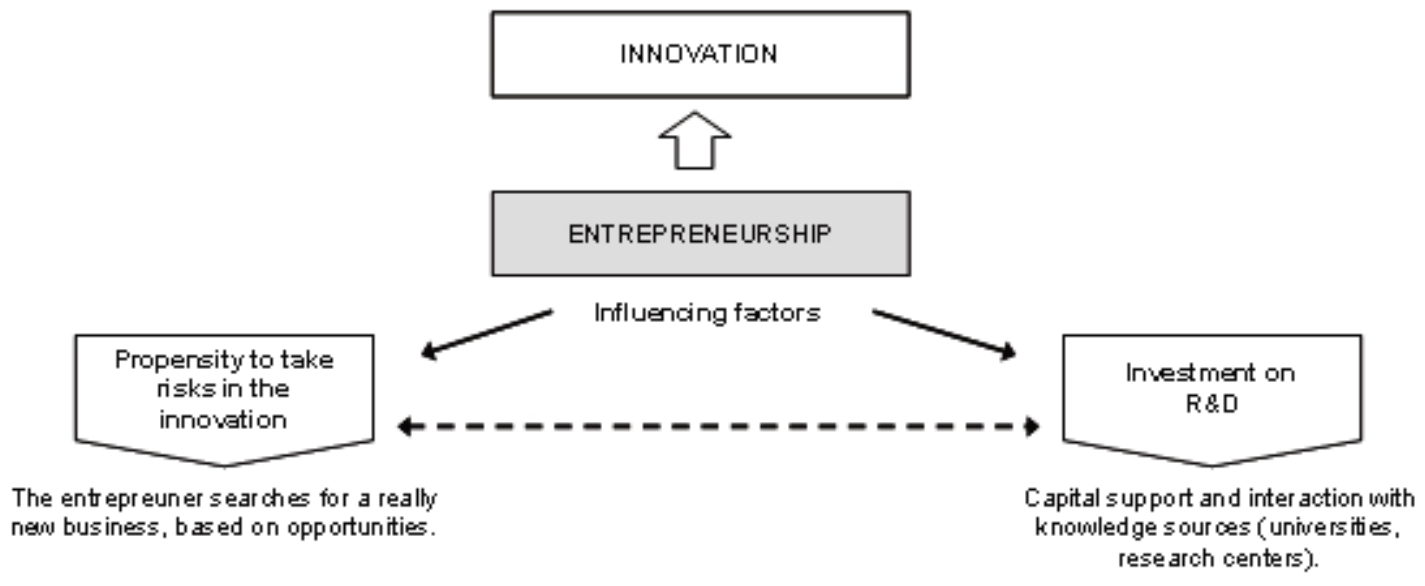

Figure I. Influencing factors of the entrepreneurship for the innovation

The existence of an entrepreneurial culture focused on the innovation - the essence of the schumpeterian entrepreneur - is, therefore, a fundamental element of the innovation function. However, it is important to highlight that the institutional context acts like a boundaries maker for the opportunities visualized by the innovative-entrepreneur, favoring or not innovations generation.

\section{Institutions}

The study of innovation finds its origins in Schumpeter's theory on the innovation routinization in big firms, in which it takes the form of organized patterns, centered in the area of R\&D. In this context, the innovation process would depend on the manners of information and knowledge articulation inside the firm.
However, this organizational structure cannot be dissociated from institutional dimensions. North (1993) defines the institutions as the "rules of the game" in a society - the limitations idealized by the men that give form to human interaction. It is fact that institutions affect the economy's performance, because, together with current technology, they determine the production and transaction costs that constitute the firms' total costs. Moreover, the differences in the economies' performance along the time are influenced by the way in which the institutions evolve. This way, it is not possible to imagine the innovation process, in the firm, without the influence of institutions - as limiters, boundaries makers and future horizons for the firms.

Institutions reduce the uncertainty by the fact they provide a structure to the daily life (not necessarily an efficient one) serv- 
ing as a guide for human interaction. They define and limit the set of individuals' choices - in a formal way, as in the case of norms; or informal, through agreements and conduct codes. They can be created, as the political constitutions of States; or simply to develop along the time. However, it is noticed that institutions can vary according to geographical areas or to each area's development level (North, 1993).

When institutions restrict the opportunities for the firms, their internal capabilities may not be enough, by themselves, to produce innovations. Consequently, the firms that can not differentiate themselves become focused merely on efficiency requirements. An institutional context with a contrary group of incentives leads to the prevailing conditions in many countries of the Third World. Sometimes, institutions favor non-productive redistributing activities, create monopolies instead of competence conditions, and do not induce investments on education that increase the productivity. The organizations that develop in this institutional context tend to reinforce this institutional structure that is not appropriated for innovation.

However, even considering the many countries that invest in R\&D, the development and commercialization of "new technologies for the world" has concentrated, historically, in a few countries. If great part of the variation of innovative capacity among countries is due to differences in their level of investments in R\&D, another significant part is related to differences in the productivity of their R\&D efforts, influenced by their institutions. Furman, Porter and Stern (2002) categorize these institutions in three types: common structure of innovation (what includes policies of science and technology, intellectual property, incentive mechanisms to superior education and to basic research, cumulative stock of technological knowledge, available financing option, R\&D personnel availability); the micro economic environment in which the companies compete (including the interaction between supplies and local demand conditions, presence of related industries, intensity of local rivalry, cooperation firm-government-academy for investments in $R \& D$, venture capital availability); and the reinforcement between both. Therefore, if firms face unfavorable institutions, even high investments in R\&D are not effective to generate innovations what indicates the importance of the types of institutions developed by a country for its development.

According to Bresser Pereira (1992), the understanding of the economical opportunity as an external phenomenon to the entrepreneur is important because, besides imposing a limit to entrepreneur's contribution for the economic development, it suggests which is the government's role in this same development in capitalist countries. Investment opportunities can be a result of the eventual technological progress of the firms, new discoveries of resources, modifications in the market, etc; but they can also be stimulated by the government, through a system of incentives and punishments for the investment. The last case represents a system of economical planning, in which the government creates opportunities, establishes conditions and proper incentives to the investment, according to a general plan of reorganization of the productive system. The entrepreneurs, for their turn, take advantage of these opportunities - reorganizing the production factors in the firm's level. This way, the national trajectory of innovation would be determined by the institutional context faced by the firms.

Several authors reinforce the importance of institutions for the innovation, such as: facilitated relationships with the university (Macleod, McFarlane and Davis, 1997; Rondé and Hussler, 2005), incentives to education and research (Edquist and Johnson, 1997), qualified personnel and inter-fims relationships (Rondé and Hussler, 2005), local rivalry (Martinez-Ros, 2000); the existence of patterns, in high technology industries (Yoo, Lyytinen and Yang, 2005).

But how can the firms take advantage of the opportunities generated by the institutions? With this intention, the firms organize their resources with deliberate purposes, as a consequence of the opportunities regarding to the group of existent limitations. Through the firms' effort to reach its objectives, these organizations constitute a main source of the institutional change. Therefore, it is the opportunities generated by the institutions that open space for the innovations development by the firms - which, for their turn, can cause institutional changes, impelling economic development.

In this process, the entrepreneurial spirit and the capability of exploring these opportunities are key requirements for the firm to innovate - what depends either on the information received by the entrepreneurs, as in the way in which they process this information. However, the way how entrepreneur interpret and exploit the institutions can, also, take to roads that not lead to innovation. According to North (1993), some firms can have success when violating norms, continually, intimidating the opponents. The result of this strategy will depend on the effectiveness of the monitoring and on the severity of the punishment. In environments where it is possible to "break the rules", the entrepreneur makes use of personal relationships to increase his/her power - what leads to accommodation behaviors in which stability, protection and privileges block the innovation (Zawislak, Castro-Lucas and Souza, 2007).

Figure 2 presents influencing factors of the institutional context for innovation generation.

Thus, the generation of ideas and innovations by entrepreneurs happens inside an established institutional context, that can favor or not the innovativeness. However, to have ideas trans- 
formed into innovations, the domain of abilities and competences (capabilities) assumes fundamental role and must be developed by the firms.

\section{Capabilities}

The innovation is strongly determined by the firm's capabilities, which, combined in specific and differentiated ways, can result in innovative leadership, difficult of being imitated and intrinsic to the environment in which has been originated (Nelson and Winter, 2005). Technological capabilities are the ability to develop and to exploit technological know-how, which is the application of scientific knowledge for commercial purposes (Pisano, 1990). The firm can develop technological capabilities through learning approaches and creation of routines in the firm's level. However, to generate innovations, it is essential that the firm, also, have a entrepreneurial perception of the institutional environment, as well as enterprising actions to exploit perceived opportunities. In this sense, the accomplishment of investments in R\&D is a very important action to generate new knowledge, capable of helping the company to reach a distinctive and sustainable competitive advantage.

The firm can invest in R\&D internally or externally. Internal investments are focused on personnel and assets inside the firm, dedicated to the creation of new scientific-technological knowledge or to the development of commercially viable innovations.
External investments are paid to other firms, universities, or other entities dedicated to scientific or technological research, aiming to reach the same objective (Cuervo-Cazurra and Un, 2007).

To understand the innovation process, it is important to understand how the articulation among dynamic and static capabilities evolves - what explains how the firms are, at the same time, prisoners of irreversible processes of path dependency and capable to move in new directions. There are capabilities for maintaining the firm's internal coherence, while others aim to create new routines. These last ones, the dynamic capabilities, allow transforming learning into innovation (Coriat and Weinstein, 2002). However, this learning demands investments, qualified people that are able to research new knowledge, besides an internal culture that leads to creativity.

Clearly, capabilities become more important when the firm gets larger, once the individual entrepreneur becomes less omnipresent - at same time, the chance of innovation success also increases. According to Avermaete et al (2003), with firms' accumulated knowledge stock in specific technological areas, their advanced competence in R\&D projects, production and distribution and their facilitated access to resources, big companies create barriers to the entrance of new entrepreneurs and, moreover, they are proner to obtain success in their attempts of generating innovations. In favor of the small firms, however,

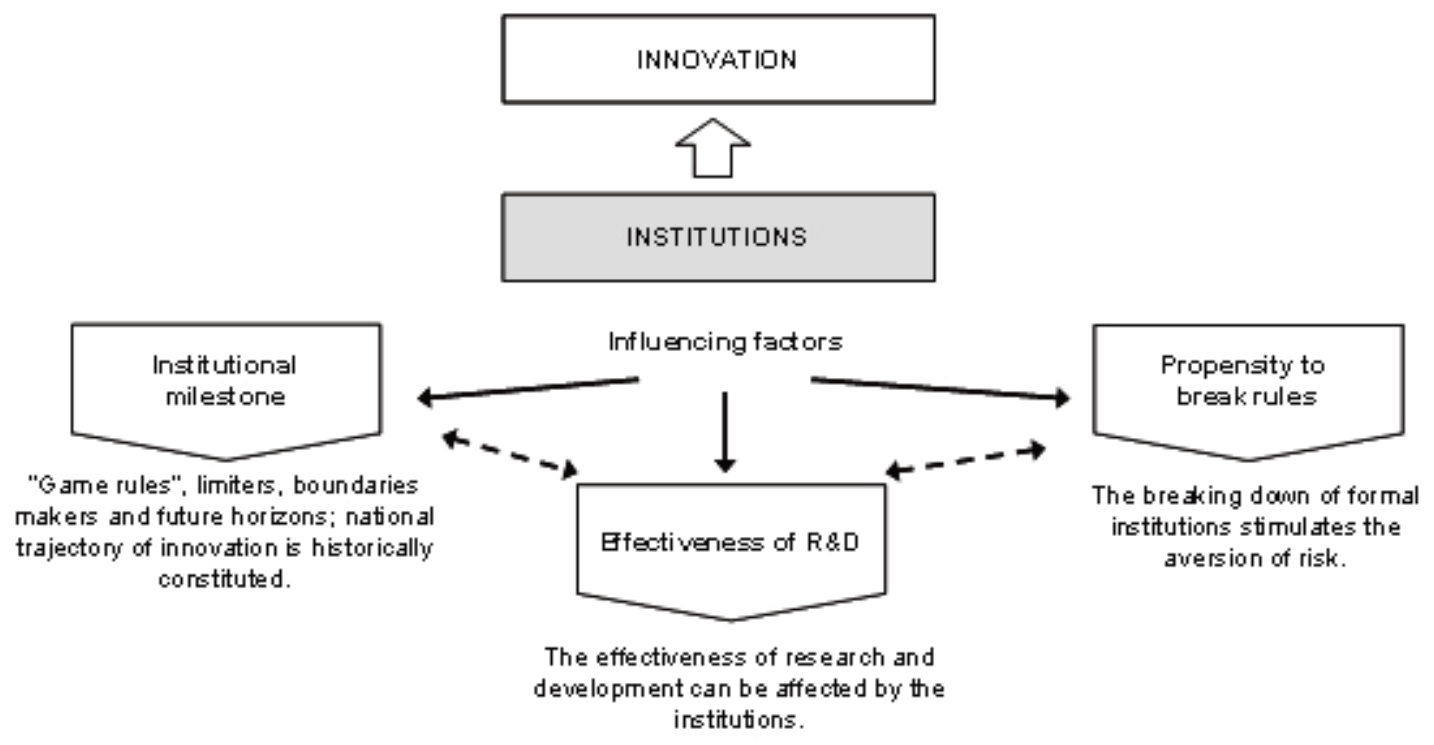

Figure 2. Influencing factors of the institutional context for the innovation 
is the fact that they are less attached to technological paths than big established firms. Besides that, in emerging countries, it is observed that big multinational firms inhibit the creation of innovative capabilities by most of the local (and smaller) firms.

According to Brascomb and Auerswald (2002), the existence of an internal infrastructure is another essential capability to facilitate the innovation process. Those authors highlight that the absence of the necessary infrastructure is a critical obstacle faced by those who generate radical innovations, in the process of moving forward from the invention to the innovation. For infrastructure it is understood not only the capacity to produce in large scale, but the complementary assets required by the market, such as distribution and services, training in the new technology, such as availability of critical equipments for research and pilot production. For Nelson (1991), the processes of development and coordination, translated into routines of organizational practices, will constitute the set of things that an organization is capable to do confidently.

If the firm decides to enter new markets, without possessing the necessary capabilities for such, its development will be at risk.According to Chandler (1992), in such cases, it is common the retraction of those firms to their original niches, in which their capabilities were more appropriate. Therefore, the firm's limit and its expansion capacity are restricted by their capabilities and capital availability.

However, capabilities development is not a trivial task, because it constitutes a challenge that can only be won through a try-and-error process (Teece, Pisano and Schuen, 1997). However, try-and-error does not mean to act in a random or chaotic way. On the contrary, all the knowledge and previous experiences are used, in a cumulative way, in the new experimentations - culminating with the validation of the capability and innovation's success. This continuous learning process is the base for the firm's distinctive capabilities. For Dosi (1988), the different trajectories and technological innovations are composed by several parts of knowledge that originate a technological paradigm. The coordination of different parts of knowledge is the capability that fosters the generation of new routines and defines the firm's technological trajectory.

Figure 3 summarizes the influencing factors of the capabilities for innovation generation.

The visualization of innovation opportunities by the entrepreneur happens inside an established institutional context, that acts as a limiter but, at the same time, can stimulate the innovation. The firm's capabilities, in their turn, make possible that the visualized opportunities be effectively transformed in innovations, since there are available financial resources.

\section{Capital cost and availability}

If innovation demands creating, inventing, taking risks, trying and making mistakes, unavoidably it demands financial resources. It is capital availability that permits the firm to invest in R\&D, from the conception of the product or service, until its placement and validation in the market (economical success), when effectively it is considered an innovation. Therefore, capital availability and accessibility are essential conditions for R\&D, resulting in the generation of innovations. In the same way, capital cost impacts the entrepreneurs/investors' perceptions about what the most appropriate financial decision is and even if it is worth to try to innovate.

Callahan and Muegge (2003) affirm that the normal sequence of financing for new enterprises is to begin with the entrepreneurs' own funds, in a second moment the family and friends' funds; for later to access "angel" investors' resources and venture capital. The use of bank financings, for those authors, usually happens when the company is already working and generating results.

That logic, however, can be inverted when the access to resources is limited, be entrepreneur's own resources or thirdparty resources. In that situation, it is inevitable that the entrepreneur drives resources to the activities that seem essential to firm's survival in short term, whileas the search for innovation is relegated to second plan. Besides that, the lack of resources as venture capital, government subsidies and, even, bank credit with low interest rates hinders businesses' innovative proposals. If the entrepreeurs have a more facilitated access to capital, they will be more likely to take the risks that are part of innovation process.

Venture capital (independent, professionally managed and focused in private companies of high growth rates) represents an important alternative to finance firms that aim to innovate (Gompers and Lerner, 200I). An additional advantage of venture capital companies is that they supply more than just capital to their partner companies. They usually bring along deep knowledge of the market and technologies, experience in promoting the successful growth of new companies, access to contacts networks and financial reinforcement (Callahan and Muegge, 2003). 


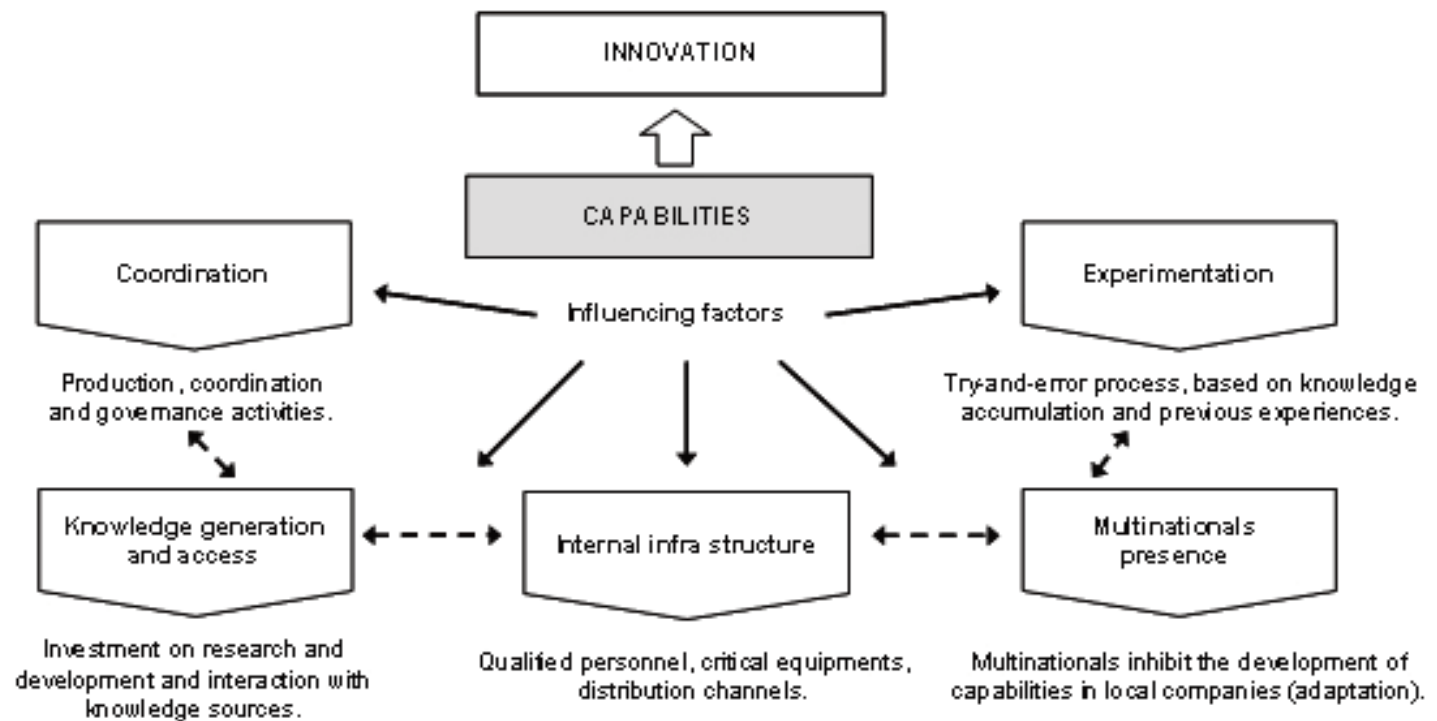

Figure 3. Influencing factors of the capabilities for innovation

In 2004, about I I 0 billion dollars were globally invested by private funds and venture capitalists, the equivalent to $0,3 \%$ of the world Gross Domestic Product. However, out of that total, only $1 \%$ was invested in Central America and South America, against $41 \%$ in North America, 39\% in Europe, $16 \%$ in Asia-Pacific and $3 \%$ in Middle East (PWC, 2005). It is necessary to highlight that the search for innovation must be supported by resources that are not marked by current interests rates, but by the perspectives of extraordinary returns that it can generate.

According to Megginson (2004), significant differences in the size and in the importance of stocks markets and venture capitalists among the countries are due to the differences in the legal systems and regulating environment. It is possible to conclude that countries whose legal and institutional environment favours property rights and where there are effective guarantying mechanisms, tend to possess better structured capital markets.

By the way, access to venture capital is yet more difficult in the case of small firms and enterprises in embryonic stages, because of the high uncertainty, asymmetry of information, difficulty in measuring intangible assets and sensibility to market conditions (Callahan and Muegge, 2003). Uncertainty is a fundamental trait of innovation and it cannot be eliminated completely, even with planning and studies. The asymmetry among entrepreneur's and investor's information is another complicating factor, as well as the measurement of the company's intangible assets, especially the innovative ones. Besides that, the sensibility of the small companies to variations in the economy is another limitation so that they are able to to capture resources in enough volume to invest in innovation.

Brascomb and Auerswald (2002) call Death Valley the moment in the time in which entrepreneurs and companies need to do the transition from the invention to the innovation. As well as in R\&D stage, this is also a critical moment of the business in which is necessary to have access to financial resources. The authors emphasize that the entrepreneurs who survived to the initial stages need, on that moment, to overcome the lack of resources (financial, but also related to time, information and people). In this stage, the few sources of available resources, even rarer in developing countries, are angel investors, established companies interested on investing in new businesses, venture capital companies, public programs and universities funds.

The capital cost can also be a limiting factor, especially considering that the investment is uncertain and needs time to generate results. The lack of capital as well as its cost refrain entrepreneurs' and firms' access to financial sources capable to stimulate the innovation. On one side, high interest rates in a country make entrepreneurs to spend more to finance their businesses and, on the other hand, they significantly reduce the availability of resources for investment in new businesses and risk activities. In that scenery, investors prefer to maintain their resources applied in stocks and the volume destined to risk activities is significantly smaller.

The influences of capital availability, in the innovations generation, are summarized in the Figure 4. 


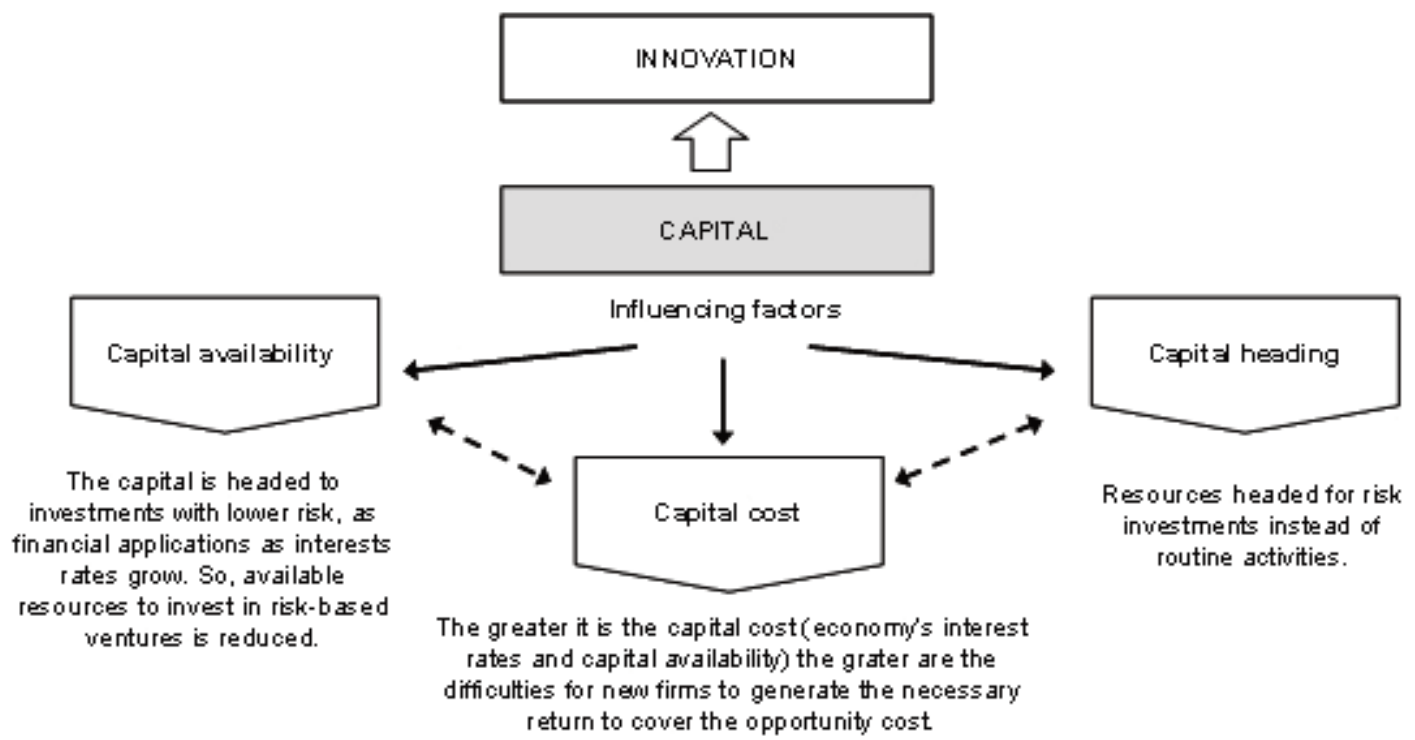

Figure 4. Influencing factors of the capital for the innovation

\section{Discussing the Relationships Among the Innovation Function Elements}

According to Montalvo (2006), the innovative behavior in organizations has been attributed to several factors, however a common characteristic observed in the current studies is that they tend to emphasize only individual determinants. Thus, a lot of the generated knowledge is fragmented because the several insights are not unified in a theoretical body focused on explaining the innovative behaviors of the firms. In spite of existing an implicit recognition that the mentioned factors interact and influence each other, it is noticed a models shortage which allow testing these influences empirically.

In this section, the innovation function elements are related, discussing the way in which their interrelations affect the companies' innovative potential.

\section{Entrepreneurship x Institutions}

Entrepreneurship is influenced by current institutions in firms' context, once these institutions define the group of opportunities to be perceived and explored by the entrepreneurs. Although entrepreunering is an inherent action to the human being, in his/her fight with the nature to develop techniques to obtain better survival conditions, those actions are influenced by the institutions - which can stimulate or restrict them. In this sense, the institutions influence the entrepreneur behaviors, determining if these ones will be, predominantly, by necessity or by opportunity.

That is, the entrepreneur, even wishing to innovate, is subject to the restrictions imposed by the "rules of the game" and by his/her perception about them. Different firms' entrepreneur actions, based on the same institutional context, can have completely different results - and these actions depend on the way in which the entrepreneurs decide to "play" and on how much they respect the rules.

In countries like Brazil, the institutions restrict innovation opportunities (due to questions regarding intellectual property violations, capital access difficulty, capital markets absence for new businesses, problems in the capital/work relations, etc), making that the decision of becoming an entrepreneur be a mere job alternative for a lot of people.This way, Brazilian "entrepreneurs", in the average, opts to invest in less risky businesses than can guarantee his/her subsistence in the short period. In other words, Schumpeterian entrepreneurship characteristics are not an institutionalized cultural trait in Brazil, causing individuals' behavior to be little focused on innovation. 
The way in which the Brazilian entrepreneur deals with the institutions, many times using the "Brazilian way" to avoid following certain rules, is a relevant point for the analysis. In environments where it is possible to "break the rules", the entrepreneur makes use of personal relationships to increase his/her power - what leads to accommodation behaviors in which stability, protection and privileges block the innovation (Zawislak, Castro-Lucas and Souza, 2007).

Proposition IA: Innovation depends on an institutionalized cultural trait which characterizes the entrepreneur.

Proposition IB: Institutional contexts that restrict innovation opportunities or in which it is possible to violate the rules inhibit entrepreneur behaviors.

\section{Entrepreneurship x Capabilities}

Individuals' entrepreneur behavior is essential for innovation, but it is not enough. There must be capabilities in the firm level, exercised through routines, that mean more than the sum of individual behaviors. The innovation process demands that the individuals' entrepreneurship is transferred to the firms' DNA, through the development of an organization and routines capable to generate inventions and to transform them in real innovations. Entrepreneurs investment options make possible the development of certain capabilities for the firm, at the same time the existent capabilities in a company can motivate more or less the individual's entrepreneur behavior (if the firm achieves good performance in the short period through non-innovative capabilities, it can reinforce the entrepreneur's accommodation in his/her disposition to innovate). There is a permanent tension between mainataining organizational coherence, on one side, and searching for new routines and capabilities, on the other side (Coriat and Weinstein, 2002).

Proposition 2A: Enterpreneur behavior, with investments in $R \& D$, positively influences innovative capabilities development by the firm.

Proposition 2B: Good performance in firms with no dynamic capabilities negatively influences the enterprising behavior.

\section{Entrepreneurship x Capital}

The available capital amount in a certain context affects the entrepreneurship in two different ways. On one side, when there are available resources, a larger number of entrepreneurs can be motivated to develop their ideas and to transform them in innovations. That is, since there are resources that tend to have a small cost, entrepreneurs tend to take the plundge and try to implement their ideas. In a country where there is capital availability, a larger number of people will take advantage from that opportunity than if they are in a situation where the access to resources is limited and the cost is higher.

On the other side (smaller resources availability), potential entrepreneurs avoid taking too much risk, such as investing their own financial resources or accessing resources whose cost is too high. In the Brazilian reality, capital cost and low availability help to explain the fact that national entrepreneurs limit themselves to open one more business, instead of trying to create a really new business (Zawislak, Castro-Lucas and Souza, 2007). In that case, opening a business is to search for an immediate income alternative and a solution for the non-employment, instead of exploring a new opportunity, as is the case of the schumpeterian entrepreneur.

Data from Bosma and Harding (2007) indicate that $12.1 \%$ of Brazilian population owns an established business, one of the highest taxes among the researched countries. Only in 2006, $3.5 \%$ of Brazilian people, between 18 and 64 years old, established a new business. However, that does not mean that there is an increase in the population's per capita income. Countries with smaller entrepreneurship rates along the time possess much larger per capita income, possibly in detriment of new companies' technological and innovative characteristics in those countries. The study points out that almost $50 \%$ of new businesses in Brazil are opened for necessity, larger index among the researched countries (Bosma and Hading, 2007) and even if the other $50 \%$ are not opened for necessity, it is not possible to affirm that they are innovative businesses as well.

Proposition 3A: A favorable economical environment stimulates, significantly, entrepreneurs who visualize businesses opportunities.

Proposition 3B: Financial resources availability, at small costs, increases entrepreneur's success chances in the transition from invention to the innovation.

\section{Institutions x Capabilities}

In spite the importance of entrepreneur's perception about the existent institutions, capabilities must be developed in the firm level to explore innovation opportunities. These capabilities are key requirement for the firm when processing the information originated from the institutional environment and interacting with it. Also, the type of capability developed by a firm can be strongly influenced by institutions. An institutional context that restricts opportunities for the firms can discourage internal ca- 
pabilities for the innovation and drive the focus on efficiency requirements.Also, geographical areas' historical conditions can influence firms' development trajectories and shape firms' capabilities.

Institutions can, still, influence firms' R\&D capabilities productivity. Researches point out that if the same R\&D investment amount is places in in two different areas, the resulting innovation degree will depend on each institutional context - that can involve access to relationships with universities and research centers, qualified R\&D personnel availability, science and technology policies, etc (Furman, Porter and Stern, 2002). Factors like rules of corporate governance and capital/work relations would also condition firms' routines, impacting their capabilities for innovation.

Proposition 4A: The specificities of the institutional context influence the routines of different types of firms' (type of capability and productivity of R\&D investments), stimulating or not, according to its nature, the innovativeness.

Proposition 4B: Capabilities to explore institutional opportunities increase the firms' innovativeness.

\section{Institutions x Capital}

Institutions concept suggest that there is a positive relationship between institutions and capital availability, cost and heading in different countries. If the institutions are the "rules of the game" in a certain environment, be formal and/or informal (North, 1993), it is inevitable that, among other things, they have effect on the capital. In what way does this relationship happens? When the country's institutions are strong and firms follow the institutionalized norms, there is an environment of little instability and smaller risk.

An institutional environment that offers larger confidence that rights and contracts will be respected contributes to reduce investors/savers' aversion to the risk. Among other consequences, that scenery increases resources availability destined to innovation and entrepreneurial activities. So, the possibility that there is a strong capital market interested in financing innovative companies is enlarged. From the entrepreneur's point of view, the chances of obtaining the necessary resources for the development of innovations increase.

In Brazil, although the last decade has seen progresses towards the consolidation of more reliable organisms, still remains the idea that it is possible to solve the issues by breaking institutional rules. The slowness of the justice in solving disputes and a certain belief in the offender's impunity contribute to the idea that, in some aspects, it is possible to obtain advantages breaking the rules. In that context, finacial resources amount destined to risk activities is likely to be smaller because investors will prefer safer opportunities. Moreover, with less available financial resources the capital cost destined to finance innovative activities increases.

Also, it is necessary to highlight that low capital availability influences the quality of countries' higher education and scientific research - creating institutions that do not favor the innovation. In summary, prevailing institutions influence capital availability and cost, as well as capital availability impacts institutions, so that, in both cases, innovation is affected.

Proposition 5: Prevailing institutional rules impact capital availability, cost and heading for innovative activities.

\section{Capabilities x Capital}

Some capabilities are essential to the firm or the entrepreneur during the innovation process, since the idea conception until taking it effectively to the market. Obtaining those capabilities is an essential condition for innovation success and the capital has the fundamental role of financing those capabilities development and acquisition. In a situation of resources restriction, certain essential capabilities may not exist in the company and compromise the innovation process. Recovering Brascomb and Auerswald's argument (2002), to innovate demands from the firms a certain infrastructure and complementary assets that, if if non-existent, need to be developed.

The lack of resources and/or its high cost significantly influence entrepreneur's access to essential capabilities. Acquiring them from the market or developing them internally turns out to be unviable. Consequently, firms will lack the required capabilities to develop innovations and to increase business' chances of survival. The lack of knowledge (technical, organizational and marketing related, for instance), limited for the lack of funancial resources, restricts firms' and entrepreneurs' innovative potential.

On the other hand, it is also possible to argue that the existence of some certain capabilities in the firm facilitates it access to credit lines and financing, fostering innovation. They are, therefore, internal competences that enable some firms to obtain resources that other ones can not get or do not even know that exist. 
Proposition 6A: Capital cost and availability influence the acquisition and development of essential capabilities by the innovative firm.

Proposition 6B: The existence of certain capabilities facilitates the access to capital destined to innovation.

\section{The Firm Size as a Moderator of the Relationship Among Innovation and its Elements}

Firms with different characteristics are influenced in different ways by the fundamental elements of innovation. Souitaris (2002) empiric results demonstrate that different elements have different impacts on innovation according to the type of firms (as defined by Pavitt, 1984). He criticizes the idea that there is a group of innovation determinants that influence in the same way all the firms and argue that moderators for this relationship should be explored. In this sense, this study proposes that different types of firms - in this analysis characterized by different sizes - moderate the relationship among the elements presented here and the innovation.

Proposition 7: The company size is a moderator in the relationship among the previously presented elements - entrepreneurship, institutions, capabilities, capital - and the innovation.

For enterprising individuals and small businesses, capabilities are less likely to influence innovation than do the other elements presented. This company type has its innovation process based on the schumpeterian entrepreneur role, capable to accomplish new combinations and arrangements through his/her personal action. In this case, the entrepreneur assumes the role performed by R\&D departments in big companies, and innovation depends essentially on his/her (limited) rationality and his/her choices - personifying the firm's capabilities. Doubtless, capital access on the part of this entrepreneur is a key factor so that he/she can take risks, investing in innovations and in his/her firm's development. The institutions also affect entrepreneur's innovativeness, restricting or offering opportunities that must be perceived and explored by him/her.

Small and medium sized enterprises are still plenty dependents on individual enterpreneurial actions, however they demand the development of internal routines - firm's capabilities - that allow them to develop innovations. While entrepreneur's ideas and choices have a central role in these firms innovativeness, it becomes more difficult that the whole innovation process can be conducted by a single in- dividual, as the firm has its size increased.The access to venture capital is a little more facilitated by the fact that this firm type already has concrete results in the market and offers a smaller uncertainty degree to the investors. At the same time, once they are smaller firms, they still have their capabilities quite influenced by the institutional context with which they need to be able to deal.

Big companies do not face significant restrictions in obtaining resources, they can destine their own capital for R\&D investments or capture external resources with that purpose. Unavoidably, for that firm type, innovation must be transformed in routines, without depending on the entrepreneur's role. Capabilities development - routines with the objective of stimulating innovation - is indispensable so that there is a favorable environment to the invention and innovation inside the firm. The existence of technological trajectories inherent to the firm facilitates the development of products, services and complementary processes, but limits innovation out of that context. Big companies can, eventually, influence their own institutional environment on their favor, demanding legal changes or benefits to maintain (or expand) their activities in a certain country.

Global companies, although they are subject to the institutional context of the countries in which they act, they minimize the impact of this element, addressing their innovative activities for the coutries/regions that seem more favorable. Thus, new technologies development, for instance, will be done in the country that presents favorable legal conditions and warranties of property right. Parallel to that, these companies develop capabilities that routinize and stimulate innovation in the countries that seem more appropriate and where the success possibilities are larger. For global companies, capital access is still easier, having in mind the captivation opportunities in more favorable markets.

Figure 5 synthesizes the study's research model, with base in the presented propositions regarding the relationships among the four elements of the innovation function and the firm's size moderator role. It is suggested that this model be applied to generate empiric researches that test its explanation capacity for innovations generation. 


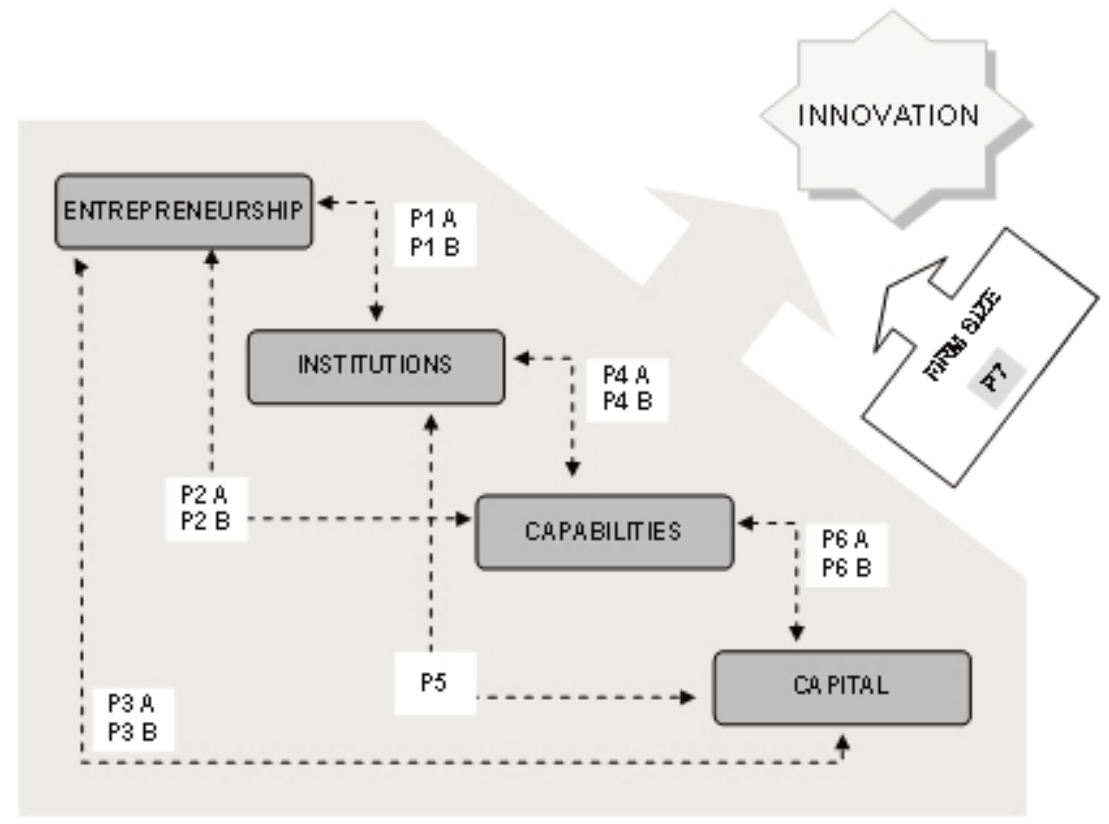

Figure 5. Proposed research model

\section{Conclusions}

Taking as a starting point the article written by Zawislak, Castro-Lucas and Souza (2007) - according to which entrepreneurs' profile and his/her awareness about the importance of investing in R\&D has great impact in firms' and countries' innovation rates - this study aimed to identify and to analyze other elements that influence innovation. For such, it was considered that any innovation is generated from a new idea and an entrepreneurial act, however it is characterized as an opportunity that exists inside an institutional context and its success depends, yet, on capabilities support and capital availability.

Thus, the paper's objective was to present innovation as a function of entrepreneurship, institutions, capabilities and capital. We work under the assumption that these interrelated elements compose a sort of function, just like the microeconomic production function. These elements were presented, their interrelations were discussed, and twelve propositions were generated. Furthermore, it was highlighted that innovation function elements influence on different ways different firms types as, for instance, firms with different sizes. Depending on firms' characteristics, from entrepreneur individuals to global companies, the impact and the importance of each element will be different, with higher or lower importance.
The study's contribution is on the search for an integrated approach of elements that influence firms' innovation, presenting an innovation function and a conceptual model that can serve as base for future empiric researches. We consider that this is just the first step towards an innovation function. Empirical research is needed to validate the elements and to understand how these interrelated elements impact on the innovative behavior of different kinds of firms.

\section{Acknowledgements}

The authors would like to thank CNPq - Conselho Nacional de Desenvolvimento Científico e Tecnológico (the Brazilian national science foundation) for supporting the implementation of this research.

\section{References}

AHMED, P.K. (1998) Culture and climate for innovation. European Journal of Innovation Management. v. I, n. I, 30-43.

AVERMAETE, T.; VIAENE, J.; MORGAN, E.J.; CRAWFORD, N. (2003). Determinants of innovation in small food firms. European Journal of Innovation Management. v.6, n. I, 8- 17.

BOSMA, N.; HARDING, R. (2007). Global Entrepreneurship 
Monitor - GEM 2006 Summary Results. London Business School/Babson School. Retrieved from the Web 6/28/2007. www.gemconsortium.org

BOTELHO, A.J.J.; DIDIER, D.; RODRIGUEZ, V.R. (2006). Impulsionando o Take-off da Inovação no Brasil: O Investidor Anjo. Proc. Enanpad. Salvador, Bahia.

BRASCOMB, L.M.;AUERSWALD, P.E. (2002). Between Invention and innovation: An Analysis of Funding for Early-Stage Technology Development. 2002. Retrieved from the Web 6/|2/2007. http://www.atp.nist.gov/eao/gcr02-84 I/gcr02-84 I pdf.

BRESSER PEREIRA, L.C. ( 1992). Desenvolvimento econômico e o empresário. RAE, v. 32,n.3, 6-I2.

BUCKLER, S.A. (1997). The spiritual nature of innovation. Research-Technology Management, mar.-apr., 43-47.

CALLAHAN, J.; MUEGGE, S. (2003) Venture Capital's Role in Innovation: Issues, Research and Stakeholder Interests. In The international Handbook of Innovation. Elsevier, 64 I-663.

CHANDLER, A. D. ( 1992) Organizational Capabilities and the Economic History of the Industrial Enterprise. The Journal of Economic Perspectives, v.6, n.3, Summer, 79-100.

CORIAT, B.; WEINSTEIN, O. (2002) Organizations, firms and institutions in the generation of innovation. Research Policy, v.3 I, 273-290.

CUERVO-CAZURRA, A.; UN, C.A. (2007) Regional economic integration and R\&D investment. Research Policy, v. 36, 227-246.

DOSI, G. (1988) Technical change and economic theory. London; New York: Pinter Publishers.

EDQUIST, C.; JOHNSON, B. ( 1997) Institutions and organizations in systems of innovation. In Systems of innovation: technologies, institutions and organizations, C. Edquist (ed.). London: Pinter.

FURMAN, J.L.; PORTER, M.E.; STERN, S. (2002) The determinants of national innovative capacity. Research Policy, v. 3 I , 899933.

GOEDHUYS, Micheline. (2007) The impact of innovation activities on productivity and firm growth: evidence from Brazil. Working Paper Series. UNU-MERIT. Retrieved from the Web 6/15/2007. http://www.merit.unu.edu/publications/wppdf/2007/ wp2007-002.pdf

GOMPERS, P; LERNER, J. (200I) The venture capital revolution. Journal of Economic Perspectives. v. I5, n.2, Spring, I45-I68.

LARRAIN, F. B. (2006) Innovación en Chile: Análisis e Propuestas. Serie de Estúdios Economicos e Sociales. Retrieved from the Web 6/20/2007. http://www.iadb.org/publications/

LEDERMAN, D.;SAENZ, L. (2007) Innovation and Development around the World, 1960-2000. 2005. Office of the Chief Economist. Latin America and the Caribbean The World Bank. Retrieved from the Web 6/22/2007. http://econ.worldbank.org

MACLEOD, G.; MCFARLANE, B.; DAVIS, C.H. (1997) The knowledge economy and the social economy. International Journal of Social Economics, v.24, n. I I, I 302-I 324.

MARTINEZ-ROS, E. (2000) Explaining the decisions to carry out product and process innovations: the Spanish case. The Journal of High Technology Management Research, v. I0, n.2, 223 242.

MEGGINSON,W. (2004) Toward a Global Model of Venture Capital? Journal of Applied Corporate Finance I6(I): 8-26.

MONTALVO, C. (2006) What triggers change and innovation. Technovation, v.26, 312-323.

NELSON, R. R. (199I) Why Firms Differ, and How Does it Matter? Strategic Management Journal, v. I2, winter, 6I-74.

NELSON, R. R. ;WINTER, S. G. (2005) Uma teoria evolucionária da mudança econômica. Campinas, SP: UNICAMP.

NORTH, Douglas C. (1993) Instituciones, cambio institucional y desempeño económico. Mexico, Fondo de Cultura Económica.

PAVITT, K. ( 1984) Sectoral patterns of technical change: towards a taxonomy and a theory. Research Policy I3, 343-373.

PISANO, G.P. (1990) The boundaries of the firm: an empirical analysis. Administrative Science Quarterly 35, I53-I 76.

PRICEWATERHOUSECOOPERS (PWC). (2007). Institutional Website. Retrieved from the Web 6/18/2007. http://www.prw.com

RONDÉ, P.; HUSSLER, C. (2005) Innovation in regions: What does really matter? Research Policy, v.34, n.8, I I 50- I I 72. 
SCHUMPETER, Joseph A. (1942) Capitalismo, Socialismo e Democracia. Rio de Janeiro, Fundo de Cultura.

SOUITARIS,V. (2002) Technological trajectories as moderators of firm-level determinants of innovation. Research Policy, v.3 I, 877-898.

TEECE, D.J.; PISANO, G.; SCHUEN,A. ( 1997) Dynamic capabilities and strategic management. Strategic Management Journal, v. I8, n.7, 509-533.

VENKATAMARAN, S. (1997) The distinctive domain of entrepreneurship research. In Advances in entrepreneurship, firm emergence, and growth. Katz, J.A. (ed), PP. II9-138. Greenwich, Connecticut:JAl Press.

WHEELWRIGHT, S.C.; CLARK, K.B. ( I 992) Revolutionizing product development. New York:The Free Press.

YOO,Y.; LYYTINEN, K.;YANG, H. (2005) The role of standards in innovation and diffusion of broadband mobile services: the case of South Korea. Strategic Information Systems, v. I4, 323-353.

ZAWISLAK, P.A.; CASTRO-LUCAS, C.L.; SOUZA, E.C; (2007) R\&D, Entrepreneurship and innovation in Brazil: where is the missing link? In Proc. IAMOT. Miami (USA). 